\title{
Investigation of the Effects of Cellulose Derivatives on the Kinetics of Drug Release from Cellulose-Based Hydrogel Using a Response Surface Method
}

\author{
S. Lefnaoui and N. Moulai-Mostefa \\ Faculty of Sciences and Technology, University of Medea, \\ 26001 Medea, Algeria. \\ E-.mail: sonia_lefnaoui@yahoo.fr
}

\begin{abstract}
The aim of this work was to investigate the effects of the nature and concentration of cellulose derivatives on the release kinetics of ibuprofen from hydrogel matrices using a response surface method (RSM). A series of cellulose derivatives, as methyl, hydroxyethyl, hydroxypropyl and hydroxypropyl methyl celluloses (MC, HEC, HPC and HPMC) were used as polymer platforms and their impacts on drug release were studied and compared to those obtained with a reference formulation prepared with HEC. It was shown that the use of HPMC in the gel formulation contributes to the improvement of drug release and consequently its biodisponibility. Indeed, the increase in HPMC concentration forms a controlled system release because polymer chains relaxation. The drug is released under the effects of two phenomena: diffusion and relaxation of polymeric chains. Thus, the kinetic release passes from the kinetics of case II towards Fickian diffusion.
\end{abstract}

Keywords: Cellulose derivatives, Hydrogel, Formulation, Release kinetics, RSM.

\section{INTRODUCTION}

$\mathrm{G}$ els are semisolid networks containing two interpenetrating phases, a gelling agent and liquid. When the liquid is water, these systems are called hydrogels. Hydrogels have the particularity to absorb and release water solutions in a reversible manner (Robinson et al., 1993).

Among the polymers used to form hydrogels, polysaccharides of natural origin have interesting and original properties in comparison with synthetic polymers (Manjanna et al., 2010). In the last decade, cellulose ethers were used in many pharmaceutical formulations (Bajpai et al., 2008). Their use as matrices in the formulation of hydrogels has received an increasing attention because of their smart swelling behavior and biocompatibility (Hirsch and Spontak, 2002; Faroongsarng and Sukonrat, 2008; Sannino et al., 2009). Depending on the structure of the particular cellulose ether used, the drug release results from the complex combination of swelling, diffusion and erosion mechanisms. 
Lefnaoui, S. Mostefa, N.M.
The most common cellulose ether derivatives include hydroxyethyl cellulose (HEC), hydroxypropyl cellulose (HPC), methylcellulose (MC) and hydroxypropyl methylcellulose (HPMC). The chemical and physical characteristics of cellulose derivatives used in pharmaceutical applications have been described in relation to their use in sustained-release formulations (Chang et al., 2010). So, the use of HPMC in control drug release has been widely investigated (Salsa et al., 2003; Kiil and Dam-Johansen, 2003; Nakayama et al., 2009). However, little information discusses the drug-release processes from both MC and HPC (Sultana et al., 2006; Alvarez-Lorenzo et al., 2000; Marsano et al., 2003). It was suggested from the controlled release studies that HPMC encourages a strong, tight gel formation compared to other derivatives. As a result, drug-release rates have been sustained longer with HPMC than with equivalent levels of MC, HEC, or CMC. For these reasons, HPMC is considered as a polymer of choice over other cellulose ethers.

Feroro et al. (2008) have investigated the self-diffusion of water and other solvent, in hydrogels made of HPMC, HEC and HPC of varying polymer weight fraction and molecular weight. They found that the solute diffusivity is not significantly affected by the substitution type of the cellulose ether. The polymer matrix displayed the same retarding effect at equal weight fraction. Their results suggest that solute molecules can only diffuse in the void space occupied by the solvent.

Many models and mechanisms were proposed in the literature (Peppas et al., 1980; Siepmann and Peppas, 2001) in order to describe the drug release from delivery systems based on swellable cellulose derivatives.

The objective of this work was the evaluation of the effects of the nature and concentration of cellulose derivatives on the drug release kinetics. A hydrogel formulated with HEC and containing ibuprofen as drug was taken as reference. In this formulation, HEC was replaced by MC, HPC and HPMC respectively. For this purpose, response surface method (RSM) was employed in order to investigate the influences of individual factors and their interactions on the release kinetics of the formulated hydrogels.

\section{MATERIAL AND METHODS}

\subsection{Materials}

Four different water-soluble cellulose ethers polymers: hydroxyethyl cellulose (HEC), hydroxypropyl cellulose (HPC), methylcellulose (MC), and hydroxypropyl methylcellulose (HPMC) were used as received from Hercules (USA). All other chemicals are of analytical or pharmaceutical grade and, were used without further purification.

Journal of Pharmaceutical Technology, Research and Management (JPTRM), Volume 1, May 2013 


\subsection{Preparation of ibuprofen hydrogels}

The gel components were put in a volume of water which supports the drug dissolution with the addition of sodium hydroxide solution, under vigorous agitation. After the addition of two alcohols quantities, the polymer powder was added gradually in the aqueous solution. The mixing of aqueous gel was maintained for $30 \mathrm{~min}$. Thus, the prepared gel was left at rest during 24 hours at ambient temperature so that the macromolecules can adopt a stable arrangement in solution. Hydrogel formulations containing ibuprofen (5\% in wt.) were prepared according to the factor compositions listed in the design matrix.

\subsection{Drug release from hydrogel matrix}

In vitro drug release studies were realized by placing loaded sample in definite volume of releasing medium at $37^{\circ} \mathrm{C}$, during $2 \mathrm{~h}$. The amount of drug release was measured using a spectrophotometer at $235 \mathrm{~nm}$ (Thermospectronic scientific Helios UV-VIS spectrophotometer). The release kinetics mechanism was analyzed according to the equations of zero order (Eq. (1)), Higuchi (Eq. (2)), Korsmeyer et al. (Eq. (3)) and Peppas and Sahlin (Eq.(4)) (Higuchi, 1963; Korsmeyer et al., 1983; Peppas and Sahlin, 1989):

$$
\begin{gathered}
\mathrm{M}_{\mathrm{t}} / \mathrm{M}_{\infty}=\mathrm{k}_{0} \cdot t \\
\mathrm{M}_{\mathrm{t}} / \mathrm{M}_{\infty}=\mathrm{k}_{\mathrm{h}} \cdot t 1^{12} \\
\mathrm{M}_{\mathrm{t}} / \mathrm{M}_{\infty}=\mathrm{k}_{\mathrm{p}} \cdot t n \\
\mathrm{M}_{\mathrm{t}} \mathrm{M}_{\infty}=\mathrm{k}_{1} \cdot t m+\mathrm{k}_{2} \cdot t 2 m
\end{gathered}
$$

where $\mathrm{M}_{\mathrm{r}} / \mathrm{M}_{\infty}$ is the fraction of drug released; $\mathrm{k}_{0}, \mathrm{k}_{\mathrm{h}}$ and $\mathrm{k}_{\mathrm{p}}$ are kinetic constants; $n$ is a exponent which depends on the release mechanism and on the shape of swelling device. $\mathrm{k}_{1}$ is the diffusional constant; $\mathrm{k}_{2}$ is the relaxational constant and $m$ is the diffusional exponent which depends on the geometrical shape of the releasing device through its aspect ratio.

\subsection{Experimental design}

Response surface method (RSM) and in particular a D-optimal design was applied to evaluate the influence of the nature and concentration of polymers on the gel properties. RSM is a statistical technique for designing experiments, building models, evaluating the effects of several factors, and searching optimum conditions for desirable responses (Myers and Montgomery, 2002).

Journal of Pharmaceutical Technology, Research and Management (JPTRM), Volume 1, May 2013
Investigation of the

Effects of Cellulose

Derivatives on the

Kinetics of Drug

Release from

Cellulose-Based

Hydrogel 
Lefnaoui, S. Mostefa, N.M.
The D-optimal method is relatively a new technique, related to response surface methodology, used for carrying out the design of experiments, the analysis of variance, and the empirical modelling. Plans with high D-value are constructed from the data by a computer algorithm.

The main effects of three independent factors $\left(X 1, X_{2}\right.$ and $\left.X_{3}\right)$ were investigated using a D-optimal design (Table 1). $\mathrm{X} 1$ and $\mathrm{X}_{2}$ are quantitative factors and represent the polymer and water concentrations respectively. $\mathrm{X}_{3}$ represents the polymer nature where the value (-1) is allowed to the low level and (+1) to the high level in the studied field. For HEC and HPC, $X_{1}$ varies between 5.0 and $6.0 \%$ (in wt.) and, $X_{2}$ varies between 73.5 and $74.5 \%$ (in wt.) However for MC and HPMC, $\mathrm{X}_{1}=$ varies between 3.0 and $4.0 \%$ (in wt.) and, $\mathrm{X}_{2}$ varies between 75.5 and $76.5 \%$ (in wt.). These values were deduced from a preliminary study. For the responses, the constants of the Korsmeyer model (Kp and $\mathrm{n}$ ) were selected for this study.

Table 1: Factors and their levels

\begin{tabular}{cccc}
\hline Factor & Specification & Experimental Field & Unity \\
\hline$X_{1}$ & Polymer concentration & -1 to 1 & $\%$ in wt. \\
$X_{2}$ & Water concentration & -1 to 1 & $\%$ in wt. \\
$X_{3}$ & Polymer nature & HEC, HPC, MC, HPMC & \\
\hline
\end{tabular}

Experimental data were fitted to a second-order polynomial model and regression coefficients were obtained. The generalized second-order polynomial model used in the response $\left(\mathrm{Y}_{\mathrm{i}}\right)$ surface analysis was as follows:

$$
\begin{aligned}
Y= & a_{0}+a_{1} X_{1}+a_{2} X_{2}+a_{3} X_{3}+a_{11} X_{1}^{2}+a_{22} X_{2}^{2}+a_{33} X_{3}^{2} \\
& +a_{12} X_{1} X_{2}+a_{13} X_{1} X_{3}+a_{23} X_{2} X_{3}
\end{aligned}
$$

Where $\mathrm{a}_{0}, \mathrm{a}_{\mathrm{i}}$ and $\mathrm{a}_{\mathrm{ij}}$ are the regression coefficients, $\mathrm{Y}$ is the response and $\mathrm{X}_{1}, \mathrm{X}_{2}$ and $\mathrm{X}_{3}$ the independent factors. The model of surface response corresponding to the D-optimal design takes into account all the principal retained factors and their interactions.

\section{RESULTS AND DISCUSSION}

\subsection{Preliminary experiments}

A reference gel based on HEC was characterized in terms of sustained release of drug. The release study on the HEC-based gel was realized by using the

Journal of Pharmaceutical Technology, Research and Management (JPTRM), Volume 1, May 2013 


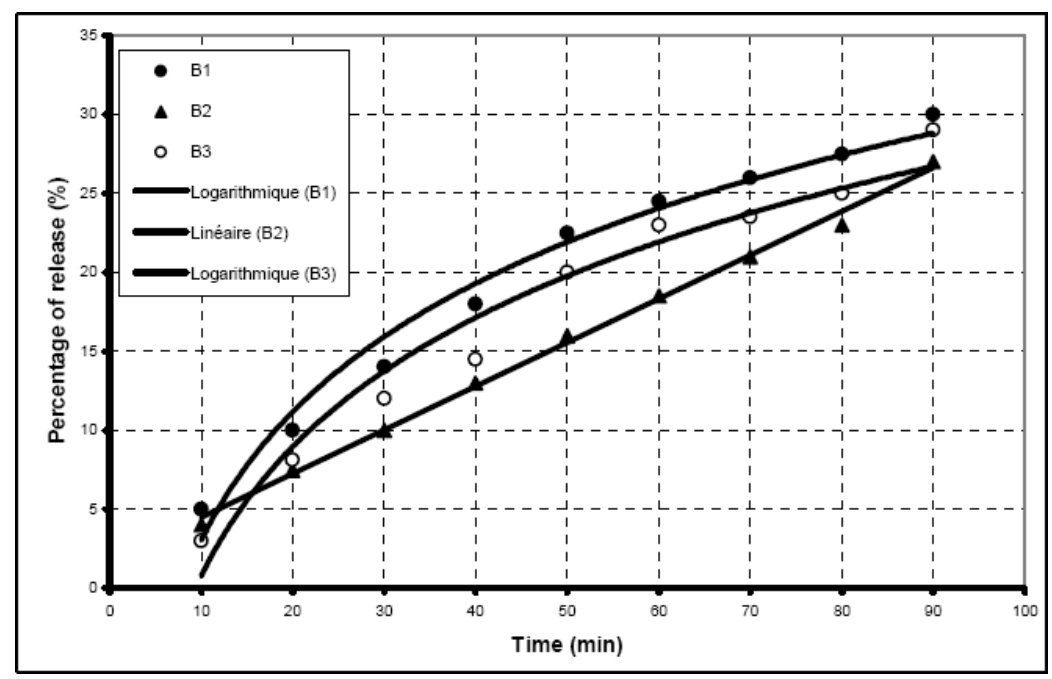

Investigation of the Effects of Cellulose Derivatives on the Kinetics of Drug Release from Cellulose-Based Hydrogel

Figure 1: Percentage of drug release as a fuction of time of the reference formulation

dissolution test. This test makes it possible to obtain the profiles of dissolution which result in the quantity of drug released according to time (Figure 1).

From this figure, we can note that the percentage of drug release increases with the time to reach around 90 min a maximum value (around 27\%). The same behavior is observed for two batches, however, for the third batch, there is an almost linear evolution. Nevertheless, it should be noted that the amount released after $90 \mathrm{~min}$ is the same for all three samples.

The rate of the release of drug (ibuprofen) according to time is presented in Figure 2.

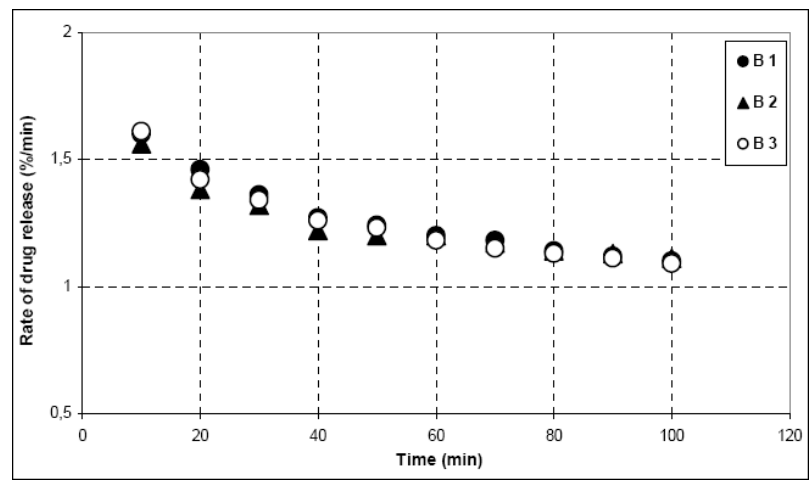

Figure 2: Rate of drug release versus time of the reference formulation 
Lefnaoui, S. Mostefa, N.M.
This rate was calculated by differentiating the function of the cumulative fraction versus time.

It appears from the presented curves, the existence of two quite distinct zones for the three studied batches (B1, B2 and B3). In the first, a release of $50 \%$ of drug is obtained in the first $30 \mathrm{~min}$. The second zone corresponds to a decrease in the rate of release. Indeed, at the end of $90 \mathrm{~min}$, the drug release reaches a constant value corresponding to a maximum release. This observed behavior can be explained as follows: during the drug absorption by diffusion, through the skin, its capacity of penetration is very fast at the beginning, then the diffuse layers saturate in relation to the diffusion coefficient of ibuprofen through the transdermic walls, that slowed down the diffusion of the drug and thus the release from the gel. This is characterized by the first zone of dissolution where a rapid drug release is observed, then a second zone where a deceleration of drug release is observed corresponding to its saturation at the surface and thus the rate tends to a constant value. The same results were observed by Langer and Peppas (Langer and Peppas, 1981). They postulate that for the second zone, the gel reached its rate of maximum swelling, a deceleration of drug release is observed at the time of its saturation.

These observed behaviours were fitted in mathematical models describing the release kinetics. The models retained for this study are of Korsmeyer and of Peppas and Sahlin respectively. The first model which is a general model, where the constant of dissolution ( $\mathrm{kp}$ ) as well as the diffusion exponent (n) give information about the phenomenon which prevails at the time of dissolution. The second model (Peppas and Sahlin) expresses the competitive relation which exists between the diffusion and the relaxation of the polymer chains forming the gel matrix.

Each model is applied to the whole of the experimental results translating the cumulated percentage of drug contained in the reference product, dissolved according to time. The calculation of the characteristic parameters of the various models was obtained by mathematical adjustment. The mathematical models were applied with the assumption that the cumulated percentage of drug is $100 \%$. The results of this statistical analysis are represented in Table 2.

A first selection of the suitable model was carried out by taking into account the coefficient of adjustment (the highest). Basing on this criterion, the exploitation of the Korsmeyer model was retained in order to determine the phenomena well appearing during the drug dissolution.

The characterization of the reference product made it possible to have a data of the release kinetics parameters. These basic characteristic data will be exploited for the realization of the generic gels formulated with cellulose derivatives.

Journal of Pharmaceutical Technology, Research and Management (JPTRM), Volume 1, May 2013 
Table 2: Coefficients adjusting the parameters of different models of dissolution

\begin{tabular}{cccc}
\hline A. & Model & Parameter & Average value \\
\hline B. & Peppas and Sahlin & $\mathrm{K}_{1}$ & 2.80 \\
C. & & $\mathrm{K}_{2}$ & 3.72 \\
D. & & $\mathrm{R}^{2}$ & 0.95 \\
E. & Korsmeyer et al. & $\mathrm{K}_{\mathrm{p}}$ & 4.44 \\
F. & & $\mathrm{N}$ & 0.76 \\
G. & & $\mathrm{R}^{2}$ & 0.97 \\
\hline
\end{tabular}

Investigation of the Effects of Cellulose Derivatives on the Kinetics of Drug Release from Cellulose-Based Hydrogel

Several formulations were prepared by replacing HEC in the reference formulation by other cellulose derivatives (HPC, MC, HPMC) as shown in Table 1.

The polymer concentrations were selected in order to obtain similar formulations to the prepared one with HEC.

\subsection{D-OPTIMAL EXPERIMENTS}

\subsubsection{Statistical analysis}

The arrangements of D-optimal experiments are listed in Table 3, which include 23 sets of experiments. The tests will be performed in a random order (randomized) and within a goal of reducing systematic errors that could suffer the response measurements.

By using multiple regression analysis, the responses $\mathrm{Y}_{1}\left(\mathrm{~K}_{\mathrm{p}}\right)$ and $\mathrm{Y}_{2}$ (n) were correlated with the three design factors using the second-order polynomial (Eq. 5). The quadratic regression models are given by Eq. 6 and Eq. 7 respectively:

$$
\begin{aligned}
\mathrm{Y}_{1}= & 4.240+0.308 \mathrm{X}_{1}-0.049 \mathrm{X}_{2}-1.256 \mathrm{X}_{3}(\mathrm{HEC}) \\
& +2.266 \mathrm{X}_{3}(\mathrm{HPC})-0.820 \mathrm{X}_{3}(\mathrm{MC})-0.188 \mathrm{X}_{3}(\mathrm{HPMC}) \\
& -0.234 \mathrm{X}_{1}^{2}-0.149 \mathrm{X}_{2}^{2}+0.029 \mathrm{X}_{1} \mathrm{X}_{2}+0.137 \mathrm{X}_{1} \mathrm{X}_{3}(\mathrm{HEC}) \\
& +0.039 \mathrm{X}_{1} \mathrm{X}_{3}(\mathrm{HPC})-0.623 \mathrm{X}_{1} \mathrm{X}_{3}(\mathrm{MC})+0.447 \mathrm{X}_{1} \mathrm{X}_{3}(\mathrm{HPMC}) \\
& +0.044 \mathrm{X}_{2} \mathrm{X}_{3}(\mathrm{HEC})-0.178 \mathrm{X}_{2} \mathrm{X}_{3}(\mathrm{HPC})+0.065 \mathrm{X}_{2} \mathrm{X}_{3}(\mathrm{MC}) \\
& +0.069 \mathrm{X}_{2} \mathrm{X}_{3}(\mathrm{HPMC})
\end{aligned}
$$


Lefnaoui, S. Mostefa, N.M. 126
Table 3: Experimental matrix

\begin{tabular}{|c|c|c|c|c|c|}
\hline Run & X1 & $\mathbf{X 2}$ & $\mathbf{X 3}$ & $\mathbf{Y 1}(\mathbf{K p )}$ & $\mathbf{Y 2}(\mathbf{n})$ \\
\hline 1 & -1 & -1 & HEC & 2.01 & 0.89 \\
\hline 2 & 1 & -1 & HEC & 3.02 & 0.72 \\
\hline 3 & -1 & 1 & HEC & 2.12 & 0.88 \\
\hline 4 & 1 & 1 & HEC & 2.89 & 0.78 \\
\hline 5 & -1 & -1 & HPC & 6.07 & 0.71 \\
\hline 6 & 1 & -1 & HPC & 6.45 & 0.78 \\
\hline 7 & -1 & 1 & HPC & 5.30 & 0.80 \\
\hline 8 & 1 & 1 & HPC & 6.31 & 0.75 \\
\hline 9 & -1 & -1 & MC & 3.30 & 0.60 \\
\hline 10 & 1 & -1 & MC & 2.60 & 0.81 \\
\hline 11 & -1 & 1 & MC & 3.35 & 0.57 \\
\hline 12 & -1 & 0 & MC & 3.32 & 0.59 \\
\hline 13 & 1 & 0 & MC & 2.80 & 0.79 \\
\hline 14 & 0 & -1 & MC & 3.25 & 0.61 \\
\hline 15 & 0 & 1 & MC & 3.22 & 0.64 \\
\hline 16 & -1 & -1 & HPMC & 2.80 & 0.62 \\
\hline 17 & 1 & -1 & HPMC & 4.28 & 0.92 \\
\hline 18 & -1 & 1 & HPMC & 2.81 & 0.63 \\
\hline 19 & 1 & 1 & HPMC & 4.35 & 0.89 \\
\hline 20 & 0 & 0 & HPMC & 4.13 & 0.82 \\
\hline 21 & 0 & 0 & HPMC & 4.02 & 0.79 \\
\hline 22 & 0 & 0 & HPMC & 4.12 & 0.81 \\
\hline 23 & 0 & 0 & HPMC & 4.01 & 0.79 \\
\hline
\end{tabular}

$$
\begin{aligned}
\mathrm{Y}_{2}= & 0.774+0.0435 \mathrm{X}_{1}+0.027 \mathrm{X}_{2}+0.638 \mathrm{X}_{3}(\mathrm{HEC}) \\
& +0.0064 \mathrm{X}_{3}(\mathrm{HPC})-0.0899 \mathrm{X}_{3}(\mathrm{MC})+0.0196 \mathrm{X}_{3}(\mathrm{HPMC}) \\
& +0.0220 \mathrm{X}_{1}^{2}-0.0429 \mathrm{X}_{2}^{2}-0.0080 \mathrm{X}_{1} \mathrm{X}_{2}-0.1110 \mathrm{X}_{1} \mathrm{X}_{3}(\mathrm{HEC}) \\
& -0.0385 \mathrm{X}_{1} \mathrm{X}_{3}(\mathrm{HPC})+0.0532 \mathrm{X}_{1} \mathrm{X}_{3}(\mathrm{MC})+0.0964 \mathrm{X}_{1} \mathrm{X}_{3}(\mathrm{HPMC}) \\
& +0.0097 \mathrm{X}_{2} \mathrm{X}_{3}(\mathrm{HEC})+0.0122 \mathrm{X}_{2} \mathrm{X}_{3}(\mathrm{HPC})-0.0142 \mathrm{X}_{2} \mathrm{X}_{3}(\mathrm{MC}) \\
& -0.0077 \mathrm{X}_{2} \mathrm{X}_{3}(\mathrm{HPMC})
\end{aligned}
$$


The quality of these models and their power of prediction, are related to the variance coefficient. The good correlations between the measured values and those predicted by the model (Figure 3 and Figure 4) confirm the qualities of these models.

In addition, the two models give high values of $R^{2}\left(\mathrm{R}^{2}=0.996\right.$ for $\mathrm{Y}_{1}$ and $\mathrm{R}^{2}=0.960$ for $\mathrm{Y}_{2}$ ). These values confirm that the equations of the models are highly reliable. This indicates also that the model terms are significant. The models are also reproducible.

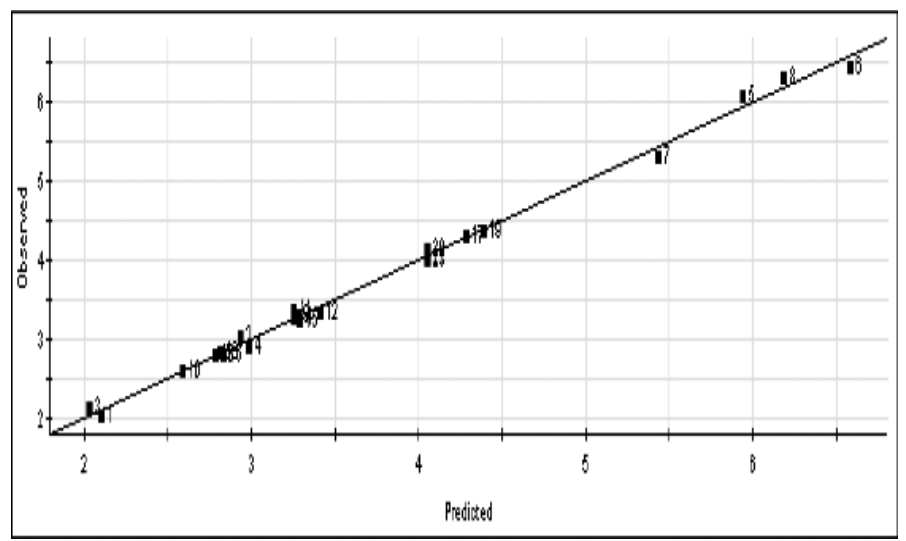

Figure 3: Relation between experimental and predicted values of the coefficient, Kp

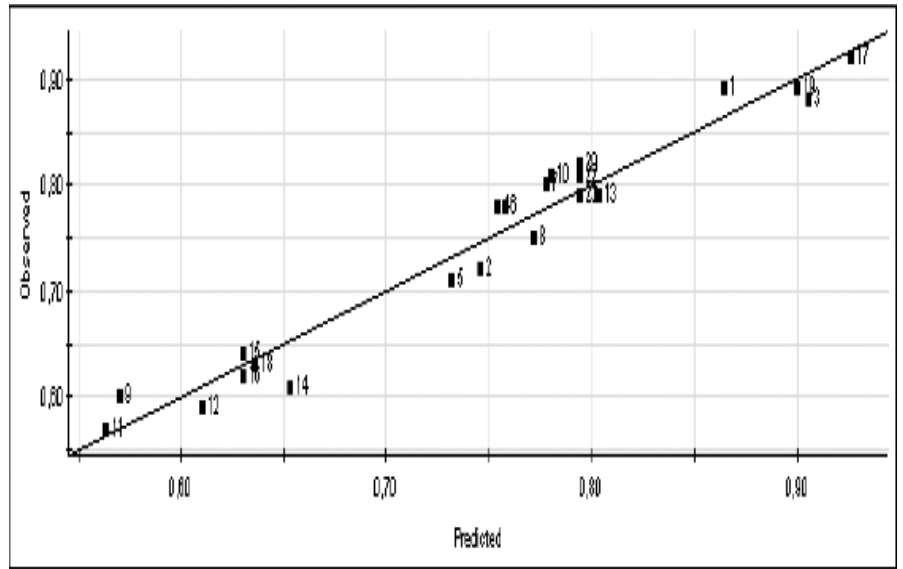

Figure 4: Relation between experimental and predicted values of the release exponent, $\mathrm{n}$
Investigation of the Effects of Cellulose Derivatives on the Kinetics of Drug Release from Cellulose-Based Hydrogel 
Lefnaoui, S. Mostefa, N.M.

The statistical significance of the ratio of mean square variation due to regression and mean square residual error was tested using the analysis of variance (ANOVA). The ANOVA of these responses demonstrated that the model is highly significant as is evident from the value of $\mathrm{F}_{\text {statistic }}$ (the ratio of mean square due to regression to mean square to real error $),\left(F_{\text {model }}=143.689\right.$ for $\mathrm{Y}_{1}$ and $\mathrm{F}_{\text {model }}=13.642$ for $\left.\mathrm{Y}_{2}\right)$ and very low probability values $(\mathrm{P}=0.001)$. The low values of probability indicate that the models are considered statistically significant.

\subsubsection{Effects of factors on the drug release kinetics}

The mechanism of drug release from matrices containing swellable polymers is complex. Some systems may be classified as either purely diffusion or erosion controlled, while most systems exhibit a combination of these mechanisms (Siepmann and Peppas, 2001). In addition, the absence of interactions between polymers and drugs in the mechanism of release from such systems has been confirmed. Madgulkar et al. (2009) have studied the presence of interactions between drug (miconazole) and excipients with help of IR. Their results confirm the absence of interactions between drug and the used polymers.

The kinetics of ibuprofen release from the various hydrophilic matrices was analyzed using the Korsmeyer equation (Eq. 3), where $\mathrm{k}$ is the apparent release rate constant that incorporates the structural and geometric characteristics of the drug delivery system and $n$ is the diffusional exponent which characterizes the transport mechanism of the drug. The transport mechanisms were classified based on the value that $n$ assumes. For thin slabs, values of $n=0.5$ indicate Fickian release, values of $0.5<n<0.9$ indicate an anomalous (non-Fickian or coupled diffusion/relaxation) drug release, whereas values of $n=1.0$ indicate a case II (relaxation-erosion controlled) drug release (Peppas and Sahlin, 1989).

Fig. 5 shows the effects of water and polymer concentration on the apparent release constant Kp of gels formulated with HEC (Fig.5-a), HPC (Fig.5-b), MC (Fig.5-c) and HPMC (Fig.5-d) respectively. In the case of HEC and HPC, it was noticed that the constant $\mathrm{Kp}$ increases with the increase in the polymer concentration. Water seems to have a negligible effect compared to that of polymer. The effect of polymer becomes significant when the concentration is higher than 5.5 (\% in wt). In the case of HEC, an optimal field is obtained for a concentration varying between 5.5 and $6.0 \%$ (in wt.). $\mathrm{K}_{\mathrm{p}}$ reaches a maximum value of about $3.13(\% / \mathrm{min})$ for HEC and an optimal value of $6.63(\% / \mathrm{min})$ for HPC. It seems that HPC which has a higher molecular weight improves the structure of gel. The rate of drug release from HPC matrix is almost the double of that obtained with HEC matrix. 

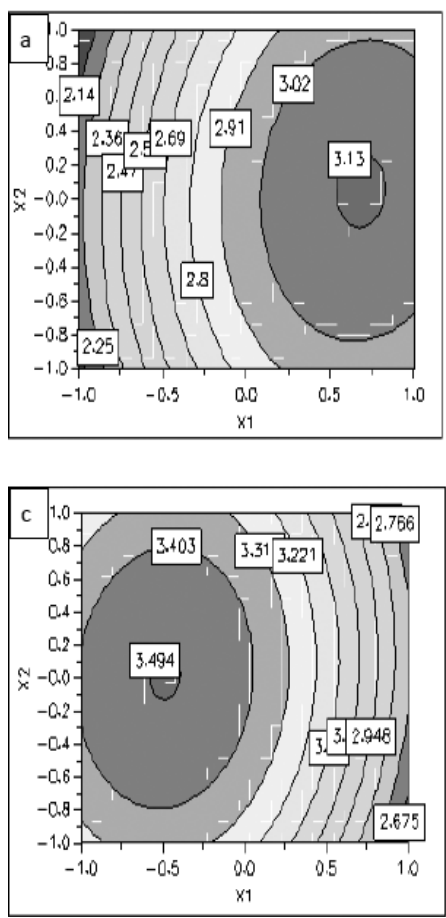
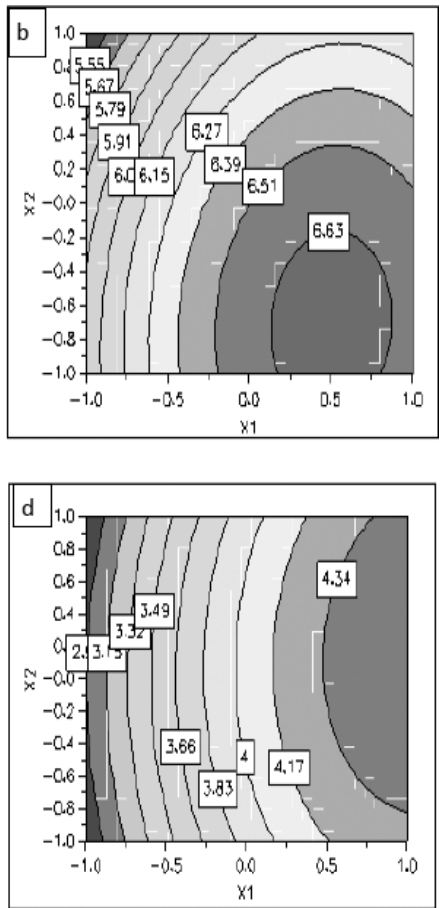

Investigation of the Effects of Cellulose Derivatives on the Kinetics of Drug Release from Cellulose-Based Hydrogel

Figure 5: Factors effects on Kp : a) HEC; b) HPC, c) MC, d) HPMC

In the case of MC, an optimal field of release is obtained for the concentration values varying between 3.0 and 3.5 ( $\%$ in wt.), whereas for HPMC, the optimal field is obtained for polymer concentration values higher than 3.75 (\% in wt.). With regard to the matrices based on HPMC, the constant $\mathrm{Kp}$ increases with the increase in polymer concentration. This observation was in accordance with previous studies that have underscored the importance of such swellable polymers and their concentrations on the release of drug from the matrix tablets (Wan et al., 1993). Matrices that contained MC and HPMC released the drug by Fikian diffusion.

Figure 6 shows the effect of the studied factors on the release exponent (n) of the Korsmeyer model. The value of $n$ indicates the nature of the diffusion which governs the drug release from the polymer matrices. In the case of HEC, the increase in polymer leads to the reduction in the value of $n$ which passes from 0.92 to 0.78 , but while keeping the same type of anomalous diffusion where there are two phenomena which contribute to the drug release: diffusion and relieving of the polymeric chains. On the other hand in the case of HPC polymer, an increase in the concentration of this polymer leads to an increase in $n$. 
Lefnaoui, S. Mostefa, N.M.
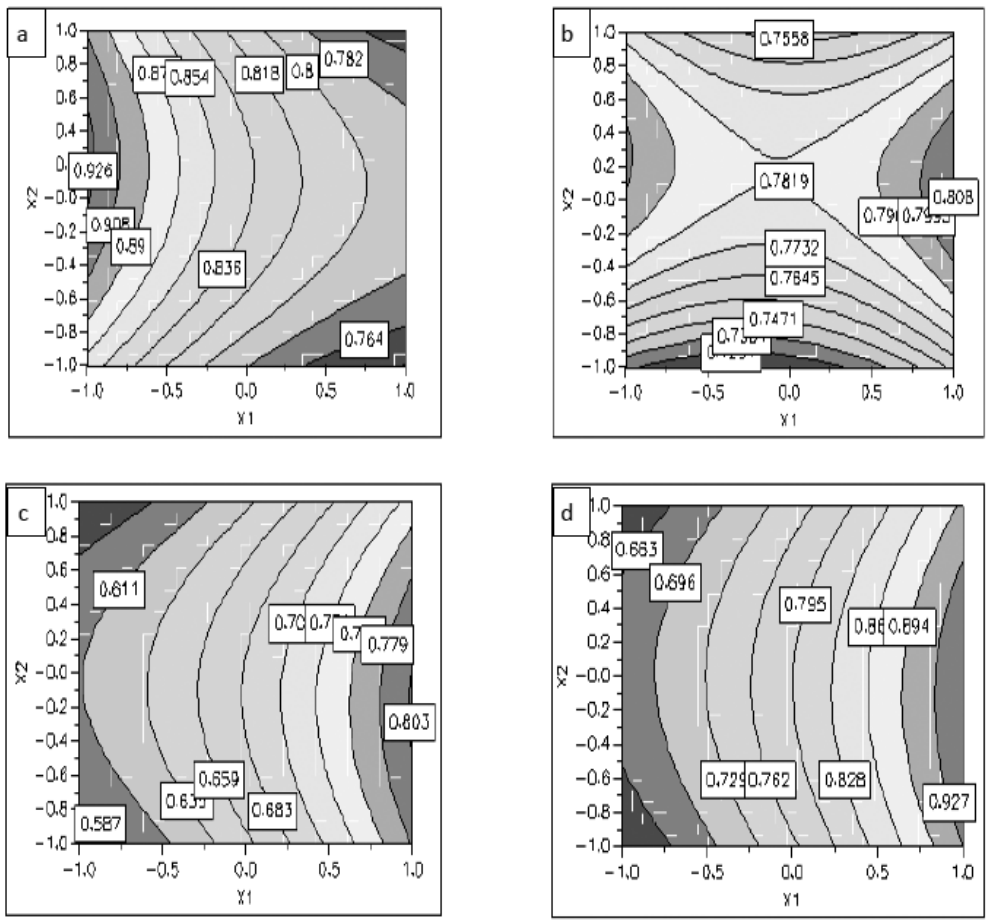

Figure 6: Effects of factors on release exponent: a) HEC; b) HPC; c) MC; d) HPMC

This increase shows the passage of Fickian diffusion towards the appearance of a second phenomenon which is the relieving of the polymeric chains. Roy and Rohera (2002) also observed that the drug release rate from HEC matrices was higher compared to the release rate from HPC matrices due to relatively higher hydrophilicity of HEC. However, the use of MC and HPMC implies an opposite phenomenon. The increase in the concentration of these polymers leads to an increase in n; it passes from 0.61 to 0.80 for $\mathrm{MC}$ and from 0.66 to 0.92 for HPMC respectively. In the two cases, the drug release through the polymeric matrix passes from kinetics of case II, towards a Fickian diffusion.

\section{CONCLUSION}

The values of the kinetic constant $\mathrm{k}$ were in accordance with those of $\mathrm{n}$, the diffusional exponent, with $\mathrm{k}$ having lower values when the transport mechanism was Case II and higher values for formulations that released the drug by Fickian diffusion. The Korsmeyer model gave a good fit to most of the dissolution data of the swellable matrices. 
The polar character of investigated polymers depends on the nature of the substituent present and the degree of substitution. The hydrophilicity of cellulose ethers increases with a decrease in an alkyl chain length. Thus, it is not surprising that HEC exhibited a considerable higher polarity as compared to HPMC, MC and HPC. The presence of small substituent groups in the structure of HEC is responsible for interaction with water and faster disentanglement threshold of polymer chains and form network for water uptake.

From the deduced results, it is clear that HPMC is proving to be the best polymer. It offers the best factors of gel formulation with a minimum concentration for better bioavailability of the drug in the diffusion and transport case II, present simultaneously in the gel. This fact clearly demonstrates the interest of copolymerization.

\section{REFERENCES}

Alvarez-Lorenzo C., Gomez-Amoza J.L., Martınez-Pacheco R., Souto C., Concheiro A. (2000) 'The stability of theophylline tablets with a hydroxypropylcellulose matrix'. Drug Dev. Ind. Pharm., Vol. 26, pp.13-20. http://dx.doi.org/10.1081/DDC-100100322

Bajpai A.K., Shukla S.K., Bhanu S., Kankane S. (2008) 'Responsive polymer in controlled drug delivery'. Prog. Polym. Sci., Vol. 33, pp.1088-1118. http://dx.doi.org/10.1016/j.progpolymsci.2008.07.005

Chang C., Duan B., Cai J., Zhang L. (2010) 'Superabsorbent hydrogels based on cellulose for smart swelling and controllable delivery'. Eur. Polym. J., Vol. 46, pp.92-100. http://dx.doi.org/10.1016/j.eurpolymj.2009.04.033

Faroongsarng D., Sukonrat P. (2008) 'Thermal behavior of water in the selected starch-and cellulosebased polymeric hydrogels'. Int. J. Pharm., Vol.352, pp.152-158. http://dx.doi.org/10.1016/j.ijpharm.2007.10.022

Ferrero C., Massuelle D., Jeannerat D., Doelker E. (2008) 'Towards elucidation of the drug release mechanism from compressed hydrophilic matrices made of cellulose ethers. I. Pulse-fieldgradient spin-echo NMR study of sodium salicylate diffusivity in swollen hydrogels with respect to polymer matrix physical structure'. J. Control. Release, Vol.128, pp.71-79. http://dx.doi.org/10.1016/j.jconrel.2008.02.006

Gu J.M., Robinson, J.R., Leung, S.H.S. (1993) 'Hydrogels, In: Encyclopedia of Phamaceutical Technology, Vol. 7, Swarbric, J. and Boylan, J.C., eds., Marcel Dekker, Inc., U.S.A., pp.459.

Hirsch S.G., Spontak R.J. (2002) 'Temperature-dependent property development in hydrogels derived from hydroxypropylcellulose'. Polymer, Vol.43, pp.123-129. http://dx.doi.org/10.1016/S0032-3861(01)00608-5

Higuchi T. (1963) 'Mechanism of sustained-action medication-theorical analysis of rate of release of solid drugs dispersed in solid matrices'. J. Pharm. Sci., Vol. 52, 1145-1149. http://dx.doi.org/10.1002/jps.2600521210

Kiil S., Dam-Johansen K. (2003) Controlled drug delivery from swellable hydroxypropyl methylcellulose matrices: model-based analysis of observed radial front movements'. $J$. Control. Release, Vol.90, pp.1-21. http://dx.doi.org/10.1016/S0168-3659(03)00122-6
Investigation of the Effects of Cellulose Derivatives on the Kinetics of Drug Release from Cellulose-Based Hydrogel 
Lefnaoui, S. Mostefa, N.M.
Korsmeyer R.W., Gurny R., Doelker E., Buri P., Peppas N.A. (1983) 'Mechanisms of solute release from porous hydrophilic polymers'. Int. J. Pharm., Vol.15, pp.25-35. http://dx.doi.org/10.1016/0378-5173(83)90064-9

Langer R.S., Peppas N.A. (1981) 'Present and future applications of biomaterials in controlled drug delivery systems'. Biomaterials, Vol.2, pp.201-214. http://dx.doi.org/10.1016/0142-9612(81)90059-4

Madgulkar A., Kadam S., Pokharkar V. (2009) 'Development of buccal adhesive tablet with prolonged antifungal activity: Optimization and ex vivo deposition studies'. Indian J. Pharm. Sci., Vol.71, pp.290-294. http://dx.doi.org/10.4103/0250-474X.56032

Manjanna K.M., Kumar T.M.P., Shivakumar, B. (2010) 'Natural polysaccharide hydrogels as novel excipients for modified drug delivery systems: a review'. Int. J. Chem. Tech. Res., Vol.2, pp. 509-525.

Marsano E., Bianchi E., Sciutto L. (2003) 'Microporous thermally sensitive hydrogels based on hydroxypropyl cellulose crosslinked with poly-ethyleneglicol diglycidyl ether'. Polymer, Vol.44, pp.6835-6841. http://dx.doi.org/10.1016/S0032-3861(03)00693-1

Myers R.H., Montgomery D.C. (2002) 'Response Surface Methodology: Process and Product Optimization Using Designed Experiments', $2^{\text {nd }}$ ed., John Wiley and Sons, New York.

Nakayama S., Ihara K., Senn M. (2009) 'Structure and properties of ibuprofen-hydroxypropyl methylcellulose nanocomposite gel'. Powder Technol., Vol.190, pp.221-224. http://dx.doi.org/10.1016/j.powtec.2008.04.075

Peppas N.A., Sahlin J.J. (1989) 'A simple equation for the description of solute release: Coupling of diffusion and relaxation'. Int. J. Pharm., Vol.57, pp.169-172. http://dx.doi.org/10.1016/0378-5173(89)90306-2

Peppas N.A., Gurny R, Doelker E., Buri P. (1980) 'Modelling of drug diffusion through swellable polymeric systems'. J. Membrane Sci., Vol.7, 241-253. http://dx.doi.org/10.1016/S0376-7388(00)80471-8

Roy D.S., Rohera B.D. (2002) 'Comparative evaluation of rate of hydration and matrix erosion of HEC and HPC and study of drug release from their matrices'. Eur. J. Pharm. Sci., Vol.16, pp. 193-199. http://dx.doi.org/10.1016/S0928-0987(02)00103-3

Salsa T., Veiga F., Teixeira-Dias J.J.C., Pina M.E. (2003) 'Effect of polymer hydration on the kinetic release of drugs: a study of ibuprofen and ketoprofen in HPMC matrices'. Drug Dev. Ind. Pharm., Vol.29, pp. 289-297. http://dx.doi.org/10.1081/DDC-120018202

Sannino A., Demitri C., Madaghiele M. (2009) 'Biodegradable Cellulose-based Hydrogels: Design and Applications'. Materials, Vol.2, pp. 353-373. http://dx.doi.org/10.3390/ma2020353

Siepmann J., Peppas N.A. (2001) 'Modeling of drug release from delivery systems based on hydroxypropyl methylcellulose (HPMC)'. Adv. Drug Deliv. Rev., Vol.48, pp. 139-157. http://dx.doi.org/10.1016/S0169-409X(01)00112-0

Sultana Y., Aqil M., Ali A., Zafar S. (2006) 'Evaluation of carbopol-methyl cellulose based sustainedrelease ocular delivery system for pefloxacin mesylate using rabbit eye model'. Pharm. Dev. Technol., Vol.11, pp.313-319. http://dx.doi.org/10.1080/10837450600767698

Wan L.S.C., Heng P.W.S., Wong L.F. (1993) 'Relationship between swelling and drug release in a hydrophilic matrix’. Drug Dev. Ind. Pharm., Vol.19, pp.1201-1210. http://dx.doi.org/10.3109/03639049309063012 